\section{MECHANICAL WEAR}

\section{SUMMER CONFERENCE AT THE MASSACHUSETTS INSTITUTE OF TECHNOLOGY}

A SPECIAL summer conference on mechanical wear was held at the Massachusetts Institute of Technology, Cambridge, Mass., on June 14-16, under the jont sponsorship of the American Society of Mechanical Engineers, the General Motors Corporation and the Chrysler Corporation, together with the Institute itself. The object of the conference was to take stock of the present knowledge and theories on this very important subject so that the most profitable directions of future research might be more clearly indicated. The absence of any general meeting on the subject in either the United States or Europe during recent years made this especially desirable.

The papers presented and accompanying discussion covered laboratory and service experience on wear in internal-combustion engines, steam turbines, brake materials, journal bearings, gears, electric brushes (in the absence of electric currents), surface plates and cutting tools. In addition, results of laboratory tests on laboratory machines simulating some of these service operations and also on specially designed wear-test machines were reported. Specifically excluded from consideration at the conference were the subjects of cavitation erosion by liquids and the wear of current-carrying electric contacts.

It was the general consensus that the wear phenomenon is exceedingly complex and depends on numerous factors. Some of these factors were discussed in considerable detail by one or more of the speakers. They included hardness, fatigue strength, gas adsorption, chemical reaction and viscosity. These discussions were too long to report here in detail, but the following notes indicate matters which were especially interesting to those present.

F. P. Bowden and D. Tabor (University of Cambridge) summarized the various ways in which rubbing surfaces can operate, depending on the quantity and type of lubricant present (in other words, full-fluid, boundary or dry), and they cited various evidence for presence or absence of metal-tometal contact in each of the three regions. The evidence showed, on one hand, intermittent contact even under conditions of sliding hydrodynamic lubrication, but on the other hand the transmission through thick oil-films of compressive stresses exceeding the yield point of the metal without direct solid contact. In a separate connexion they showed that fatty acids, which are supposed to attack metal surfaces chemically to form metal soaps which are very effective boundary lubricants, will not attack these same metal surfaces if the latter have not previously been exposed to air and moisture. R. Savage (General Electric Research Laboratory) described bis recent findings on the mechanism of the lubrication and wear of graphite. He found that the presence of oxygen or water vapour was necessary for graphite to lubricate in its familiar manner. In the absence of these gases it wears extremely badly, producing a fine dust having strong surface-active properties.

E. S. Starkman and A. G. Cattaneo (Shell Development Company) showed that the corrosive wear of piston rings increased with the amount of sulphur in the fuel, owing to formation of sulphur trioxide; it increased with the amount of tetra-ethyl lead in the fuel owing to the simultaneous presence of the halogen scavenger, and it increased sharply below the dewpoint of the water vapour in the combustion gas mixture owing to the formation of carbonic acid. $R$. Holm (Stackpole Carbon Company) proposed a relation, for the purpose of correlating wear measurements, which involves the hardness of the rubbing surfaces. He also discussed the relation of this contact hardness, as measured by an indenter, to the yield point of the metal. In addition, he showed that the measured contact-hardness depended on the size of the indenter.

H. Blok (Royal Dutch Shell, Delft) showed that the failur loading depended much more on the viscosity of the lubricant than on its oiliness or extreme-pressure characteristics. This was attributed to the ability of viscous liquids to withstand suddenly applied compressive loads. J. O. Almen (General Motors Research Laboratories) discussed the wear of gear teeth and especially that type known as scoring or welding wear. He showed a correlation between failure due to this type of wear and the product of the factors of compressive stress, sliding velocity, and the length of time the teeth are in contact. E. Buckingham (Massachusetts Institute of Technology) and G. J. Talbourdet (United Shoe Machinery Corporation) reported data on the failure of gear materials from another type of wear, namely, pitting fatigue.

J. H. Dedrick (University of Cincinnati) and John Wulff (Massachusetts Institute of Technology) described friction and wear measurements on certain ternary-bronze powder-metallurgy brake-materials containing lead, graphite and silica. They found that only a small region on the corresponding ternary diagram gave alloys having suitable characteristics as regards wear-rate and quiet operation. This area is limited to compositions containing both lead and graphite, but silica is not necessary. R. G. Larsen (Shell Development Company) tabulated and discussed all the possible adsorption and chemical reactions that could take place between the rubbing metal surface and its gas or lubricant environment. These were found to be quite numerous and sometimes complex. C. M. Allen (Battelle Memorial Institute) reported qualitative information on the minimum oil-film thickness in a fluid-lubricated journal-bearing just prior to failure. He measured the electric break-down potential of the oil film and showed that this often gave warning of impending failure.

The complete proceedings of the conference will be published shortly by the American Society for Metals, Cleveland, Ohio. J. T. BURWELL, JUN.

\section{ORIGIN OF THE SOLAR SYSTEM}

DROF. HAROLD JEFFREYS has published a paper in which 1 ind amines a number of theories proposed to explent the origin of the solar system 1 . In the earyy plift of the paper he points out that the resorance theory of the origin of the moon can no longendbe maintained; and, in fact, it was shown do years ago to be quite untenable for various asons, though it is still referred to in popular works as a possible explanation of the existence of our satellite. Dealing with the origin of the planetary system, he refers to his earlier view of a collision between the visiting star and the sun, which appeared to make some successful quantitative predictions, 